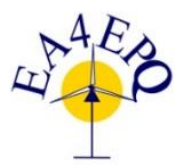

International Conference on Renewable Energies and Power Quality (ICREPQ'17)

Malaga (Spain), $4^{\text {th }}$ to $6^{\text {th }}$ April, 2017

Renewable Energy and Pourer Quality. Fournal (RE\&PQJ)

ISSN 2172-038 X, No.15 April 2017

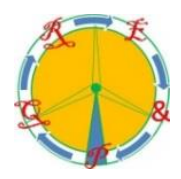

\title{
Estimating Future Grid Harmonics Due to Changing Harmonic Sources
}

\author{
William Howe ${ }^{1}$, Matthew Rylander ${ }^{2}$ \\ Power Quality Research Program (Program 1) \\ Electric Power Research Institute \\ Boulder, CO 80302 (USA) \\ Phone number: +001 720 5656888, e-mail: bhowe@epri.com, mrylander@epri.com
}

\begin{abstract}
Unprecedented changes in both end-use loads and grid management have raised concerns about increasing harmonics levels on T\&D grids. Of particular concern is now to estimate future harmonics levels for existing circuits in a reliable and repeatable way as the composition and nature of loads change.

A harmonic evaluation module that has been developed by EPRI (Electric Power Research Institute) is an effective tool for estimating the harmonic impacts on distribution systems of increased penetration of newer harmonic sources. This paper focuses on aspects of that tool and how tools and techniques of this sort can be employed to improve grid management and planning.
\end{abstract}

\section{Key words}

Filters, frequency domain analysis, frequency response, harmonic analysis, harmonic distortion.

\section{Introduction}

Modern utilities are faced with unprecedented change to both loads and grid operational practices. On the load side, generally well-behaved loads such as incandescent lighting and induction motors are increasingly being replaced with electronic lighting technologies for the former and adjustablespeed drives for the latter. Furthermore, once largely static grids are expected to become more complex and dynamic through so-called smart grid-type innovations of rapid reconfiguration and, for example, integration of widely distribution capacitors for more precise voltage control. These circumstances have prompted a concern not only for increased grid harmonics, but also for methods to anticipate what grid configurations might be more susceptible to harmonic resonance or elevated voltage distortion.

Some examples of newer residential harmonic sources whose penetration can be expected to increase substantially in the future include modern lighting technologies such as CFL (Compact Fluorescent) and LED (Light Emitting Diode) lamps, electric vehicle chargers, distributed PV (Photo Voltaic) systems, ASD (Adjustable Speed Drive) based home appliances, modern entertainment systems, and ECM (Electronically Commutated Motors) based HVAC (Heating, Ventilation, \& Air Conditioner) units.

One of the existing gaps related to modeling and simulations used for planning and diagnostic purposes has traditionally been the extensive amounts of time it takes to develop and validate the accuracy of any given system model and the lack of diversity in the load models that are applied during the simulation. As a result, most analyses involve a single representative circuit and the results are extrapolated to similar circuits in that voltage class. EPRI's database of circuits and loads attempts to address this gap by providing a large representation of pre-validated circuits in addition to a diverse database containing harmonic measurements for existing and emerging load types. The result is the ability to simulate a range of circuits in the same voltage class with multiple load mixes.

The work presented in this paper builds on previous work by EPRI that looked at the harmonic impacts of different penetration levels of CFLs for different types of circuits and source strengths [3]. The previous work likely yielded overly conservative results as by virtue of ignoring phase angle information in harmonic spectrums, the harmonic cancellation effect was not incorporated. The new work takes into account the phase angle information and looks at impact over the entire circuit whereas the previous work only focused on the harmonic impact at circuit head. Finally, the combined impact of multiple harmonic sources has been studied.

The analysis has been performed using the open source 
software named OpenDSS that has been developed by EPRI for performing various types of distribution studies [4]. EPRI has a large and still growing library of detailed models of actual distribution circuits from United States with some international representation as well. A special interface has been developed that provides a user-friendly tool for performing advanced harmonic analyses including conducting frequency scans and solving for harmonic distortion in order to evaluate the system-wide impacts of conventional and new harmonic rich loads [5]. The analysis presented in this paper has dealt with incremental harmonic impacts of the various distributed harmonic sources at specific locations and also over the entire circuits.

\section{Distributed Harmonic Sources}

In order to accurately model the existing harmonic levels in the base models of the study systems, a comprehensive monitoring exercise was carried out that involved connection of power meters to the secondary circuit of an actual service transformer in operation. The monitored service transformer has wye-wye connection, is rated at $50 \mathrm{kVA}$ and steps down from $12.47 \mathrm{kV}$ line-line to $240 / 120 \mathrm{~V}$ for service connections to four houses in a suburban neighborhood. The measurements were carried out over a continuous period of one week in the month of May of 2012. The meters captured the individual and overall harmonic trends for both currents and voltages. In addition, the meters were configured to capture 16 cycle waveform every 10 minutes. Fast Fourier Transformations (FFT) operations were carried out on these captured waveforms to extract current magnitude and phase angles of individual harmonics. Then, 95th percentile values for all such samples collected over a week were computed and the same are summarized in Table I.

TABLE I

HARMONIC SPECTRUM OF INDIVIDUAL HOUSES AND SERVICE TRANSFORMERS

\begin{tabular}{|c|c|c|c|c|}
\hline Harmonic & House\#1 & House\#2 & \multicolumn{2}{|c|}{ Transformer Combined } \\
\hline & $\begin{array}{c}\text { Magnitude } \\
\text { (\% Fund) }\end{array}$ & $\begin{array}{c}\text { Magnitude } \\
\text { (\% Fund) }\end{array}$ & $\begin{array}{c}\text { Magnitude } \\
\text { (\% Fund) }\end{array}$ & $\begin{array}{c}\text { Angle } \\
\text { (deg) }\end{array}$ \\
\hline 1 & 100.0 & 100.0 & 100.0 & 0.0 \\
\hline 3 & 8.8 & 7.9 & 8.6 & 148.6 \\
\hline 5 & 5.8 & 4.4 & 4.7 & -78.34 \\
\hline 7 & 3.5 & 2.0 & 2.9 & 199.73 \\
\hline 9 & 2.8 & 2.8 & 2.9 & 83.23 \\
\hline 11 & 1.2 & 0.9 & 1.1 & -76.3 \\
\hline 13 & 0.9 & 0.7 & 0.9 & 158.74 \\
\hline
\end{tabular}

Such a methodology is in line with the latest changes that have been recommended in industry standards on harmonics [4]. It can be seen that magnitudes for the various harmonics collected for individual houses are of same order as the combined transformer values. Therefore, the combined harmonic spectrum in the table has been used to represent the current harmonic injections into the utility systems through individual service transformers distributed over the circuits.
This allowed creation of the base cases that represent the harmonic injections for the loading mix that can be considered to be representative of year 2012 .

The proportion of power electronic based loads can be expected to increase in future. This is supported by the data on projected trends in electricity consumption for different load types in both residential and commercial categories for year 2010 -2035 as provided in EIA's Annual Energy outlook 2011 [6]. Based on this data and our knowledge about proportion of power electronic based loads today, the projection for the year 2030 is tabulated in Table II.

TABLE II

PROJECTION OF PROPORTION OF POWER ELECTRONIC BASED LOADS IN RESIDENTIAL AND COMMERCIAL CATEGORIES

\begin{tabular}{|c|c|c|c|}
\hline Load category & 2010 Actual & \multicolumn{2}{|c|}{ 2030 Projection } \\
\hline & & $\begin{array}{c}\text { Excluding } \\
\text { Electronic } \\
\text { Lighting and } \\
\text { Drives }\end{array}$ & $\begin{array}{c}\text { Including } \\
\text { Electronic } \\
\text { Lighting and } \\
\text { Drives }\end{array}$ \\
\hline Commercial & $40 \%$ & $48 \%$ & $60 \%$ \\
\hline Residential & $44 \%$ & $50 \%$ & $60 \%$ \\
\hline
\end{tabular}

The simplistic way of estimating harmonic injections in utility systems through service transformers in year 2030 could be to take the existing harmonic spectrum in Table I and multiply it by a factor of 1.5 to incorporate the anticipated growth in power electronic loads. However, in future we may have new standards in place that would limit the harmonic injection from individual loads. Such an action is expected to significantly reduce the harmonic injections into utility systems despite increase in penetration of the various harmonic sources. A more specific approach that estimates the individual and combined harmonic impact of increase in the penetration of the various load types has been followed. The additional key loads that are projected to supplement the existing loads by year 2030 are presented below. It may be noted that these assumptions are a little bit on the conservative side:

- $\quad$ Each house will have an additional $200 \mathrm{~W}$ of low PF modern lighting replacing the existing incandescent lamps. CFLs have been used to represent this load type.

- $20 \%$ of houses will have electric vehicles (EV). An AC charger rated at $3.3 \mathrm{~kW}$ has been assumed to represent this load type.

- $\quad 50 \%$ of houses will have additional $500 \mathrm{~W}$ of modern entertainment load (combination of modern TVs, media center PCs, Blu-Ray players and amplifiers)

- $\quad 80 \%$ of houses will have ECM based HVAC units replacing the conventional HVAC units.

EPRI has a library of harmonic spectrums for various load types that have been developed based on the actual testing activities carried out in the field and its laboratories. The spectra that have been used to model the above mentioned load types are presented in Table III. 
TABLE III

Current Harmonic SPECTRum of Future LoAd Mix COMPONENTS

A) MAGNITUDES

\begin{tabular}{|c|c|c|c|c|}
\hline Harmonic & \multicolumn{4}{|c|}{ Magnitude (\% Fundamental) } \\
\hline & $\begin{array}{c}\text { Low PF } \\
\text { Lighting }\end{array}$ & $\begin{array}{c}\text { Electric } \\
\text { Vehicle } \\
\text { Chargers }\end{array}$ & $\begin{array}{c}\text { Modern } \\
\text { Entertain- } \\
\text { ment }\end{array}$ & $\begin{array}{c}\text { ECM } \\
\text { based } \\
\text { HVAC }\end{array}$ \\
\hline 1 & 100 & 100 & 100 & 100 \\
\hline 3 & 75 & 8.92 & 30 & 4.9 \\
\hline 5 & 63 & 0.39 & 12 & 4.3 \\
\hline 7 & 52 & 0.26 & 13 & 5.4 \\
\hline 9 & 41 & 0.45 & 8 & 5.6 \\
\hline 11 & 30 & 0.51 & 5 & 2.3 \\
\hline 13 & 18 & 0.45 & 4 & 2.4 \\
\hline
\end{tabular}

B) ANGLES

\begin{tabular}{|c|c|c|c|c|}
\hline Harmonic & \multicolumn{4}{|c|}{ Angle (Degrees) } \\
\hline & $\begin{array}{c}\text { Low PF } \\
\text { Lighting }\end{array}$ & $\begin{array}{c}\text { Electric } \\
\text { Vehicle } \\
\text { Chargers }\end{array}$ & $\begin{array}{c}\text { Modern } \\
\text { Entertain- } \\
\text { ment }\end{array}$ & $\begin{array}{c}\text { ECM } \\
\text { based } \\
\text { HVAC }\end{array}$ \\
\hline 1 & -333 & 0 & 0 & 0 \\
\hline 3 & -111 & -129 & 187 & 132 \\
\hline 5 & -242 & 67 & 346 & 113 \\
\hline 7 & -171 & -157 & 164 & 276 \\
\hline 9 & -140 & 166 & 315 & 7 \\
\hline 11 & -233 & 172 & 124 & 186 \\
\hline 13 & -126 & 160 & 276 & 12 \\
\hline
\end{tabular}

\section{A. Circuit Selection}

A database of actual utility circuit models developed in the OpenDSS platform has been created by EPRI as a key element of the overall Grid-IQ effort. Three circuits out of the database were selected for the detailed analysis and the characteristics of these circuits are summarized in Table IV. It may be noted that all the selected circuits have a system voltage rating of $12.5 \mathrm{kV}$ and are predominantly residential in nature. The physical layout of the three circuits is shown in Fig. 1 through Fig. 3. Fig.3 also shows parallel circuits off the substation but Circuit $\mathrm{C}$ in particular has been identified. The figures identify the location of the substation in addition to the individual circuit capacitor banks. The size of the individual banks is also specified. The thickness of the line sections signifies the magnitude of power flow through them. Solid lines indicate three-phase primary, while dashed lines indicate single-phase and two-phase laterals.

TABLE IV

SELECTED CIRCUITS CHARACTERISTICS

\begin{tabular}{|c|c|c|c|}
\hline Circuit Alias & Circuit A & Circuit B & Circuit C \\
\hline System voltage (kV) & 12.5 & 12.5 & 12.5 \\
\hline Number of customers & 3297 & 1379 & unknown \\
\hline Service xfmr connected kVA & 12635 & 16310 & 30089 \\
\hline Total circuit kvar & 5800 & 1950 & 3600 \\
\hline Sub primary Voltage (kV) & 115 & 115 & 69 \\
\hline 3-Ph SCC at Sub Sec. (MVA) & 610 & 114 & 173 \\
\hline Primary circuit miles total & 15 & 48 & 15 \\
\hline
\end{tabular}

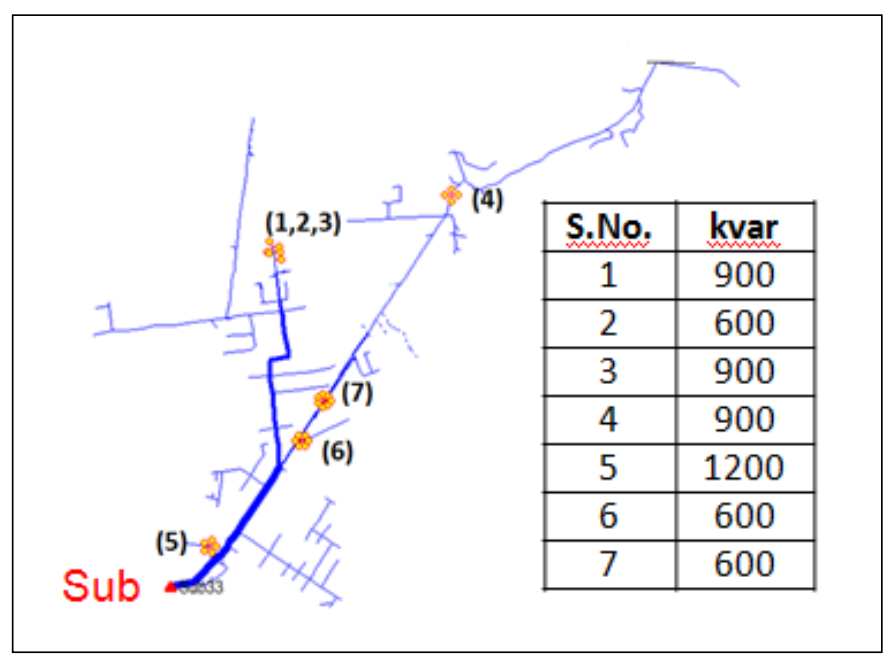

Fig. 1. Physical Layout of Circuit A

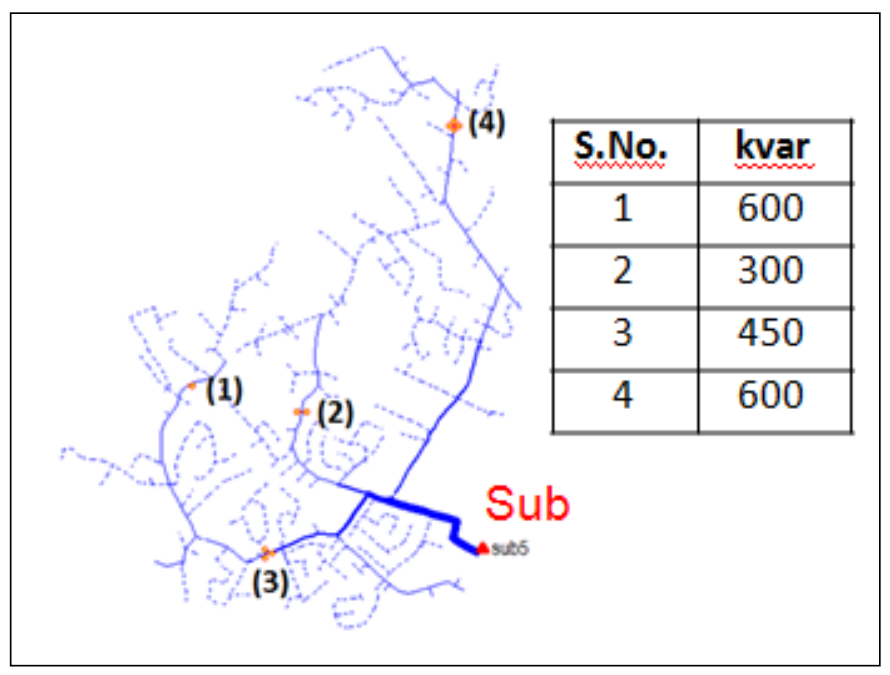

Fig. 2. Physical Layout of CircuitB

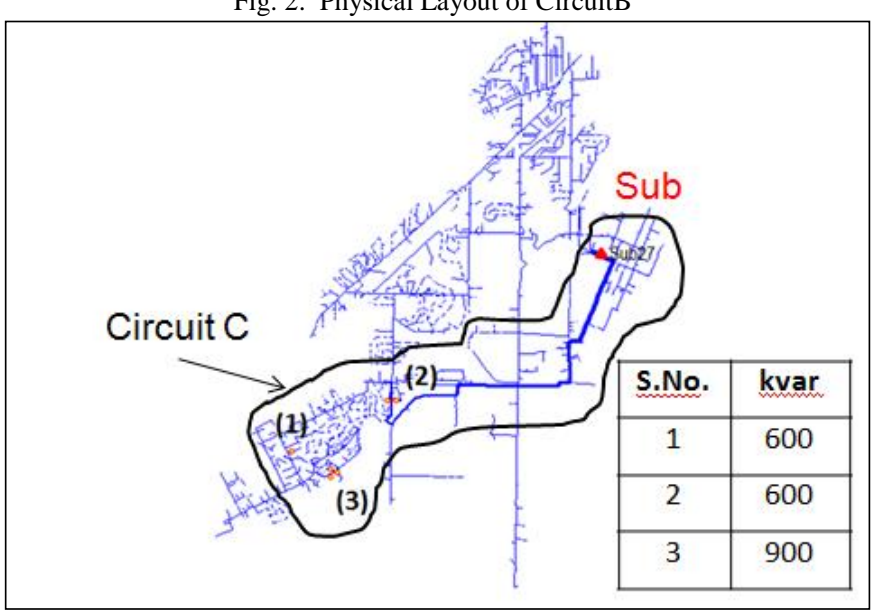

Fig. 3. Physical Layout of Circuit C

\section{B. Base Case Harmonic Injection Analysis}

For the base case analysis, the harmonic spectrum in Table I was attached to the load elements that are lumped at the 
secondary of individual service transformers. Such an approach simulates the current harmonic injections into the utility system from the sources that are distributed over the entire circuit. The individual and overall harmonic levels at the evaluation locations (circuit head and individual cap banks) for the three circuits are summarized in Table III through Table V.

The harmonic levels are not the same at different evaluation locations on any circuit. For example, third harmonic level is only $1.5 \%$ at circuit head of circuit C but increases to $5.9 \%$ at evaluation location (S. No. 2) near the middle of circuit and to as high as $8.9 \%$ at evaluation location (S. No. 3) towards end of the circuit. It may be noted that these values for Circuit C compare favorably with the actual measurements (See Table VIII) that were available for this circuit at circuit head and location (S. No. 3). The increase in harmonic levels over the length of the circuit is better visualized through the heat plot of simulated harmonics in Fig 4. This visualization technique is useful in identifying pockets in circuit that are likely to have excessive harmonic levels.

TABLE V

Base Case Voltage HaRmonic LeVels for Circuit A

\begin{tabular}{|c|c|c|c|c|}
\hline Evaluation Location & \multicolumn{4}{|c|}{ Harmonic Magnitude (\%) } \\
\hline & H3 & H5 & H7 & THD \\
\hline Circuit head & 1.41 & 2.13 & 1.64 & 3.05 \\
\hline Cap banks (S. No. 1,2,3) & 1.55 & 3.09 & 3.40 & 4.93 \\
\hline Cap bank (S. No. 4) & 1.53 & 2.93 & 3.09 & 4.6 \\
\hline Cap banks (S. No. 6 and 7) & 1.50 & 2.64 & 2.58 & 4.03 \\
\hline
\end{tabular}

TABLE VI

Base CASe Voltage HaRmonic LeVels For Circuit B

\begin{tabular}{|c|c|c|c|c|}
\hline Evaluation Location & \multicolumn{5}{|c|}{ Harmonic Magnitude (\%) } \\
\hline & H3 & H5 & H7 & THD \\
\hline Circuit head & 1.9 & 2.65 & 2.11 & 4.24 \\
\hline Cap bank (S. No. 1) & 3.94 & 3.89 & 3.26 & 7.19 \\
\hline Cap bank (S. No. 2) & 3.22 & 3.35 & 2.62 & 5.77 \\
\hline Cap bank (S. No. 3) & 3.51 & 3.55 & 2.86 & 6.28 \\
\hline Cap bank (S. No. 4) & 3.80 & 3.73 & 3.07 & 6.83 \\
\hline
\end{tabular}

Base Case Voltage HaRmonic LeVels for Circuit C

\begin{tabular}{|c|c|c|c|c|}
\hline Evaluation Location & \multicolumn{4}{|c|}{ Harmonic Magnitude (\%) } \\
\hline & H3 & H5 & H7 & THD \\
\hline Circuit head & 1.5 & 0.88 & 0.32 & 1.85 \\
\hline Cap bank (S. No. 1) & 8.3 & 3.02 & 0.5 & 9.0 \\
\hline Cap bank (S. No. 2) & 5.9 & 1.99 & 0.2 & 6.4 \\
\hline Cap bank (S. No. 3) & 8.9 & 3.32 & 0.6 & 9.7 \\
\hline
\end{tabular}

TABLE VIII

Actual Voltage Harmonic Measurements For Circuit C

\begin{tabular}{|c|c|c|c|c|}
\hline Evaluation Location & \multicolumn{4}{|c|}{ Harmonic Magnitude (\%) } \\
\hline & H3 & H5 & H7 & THD \\
\hline Circuit head & 1.8 & 1.9 & 0.4 & 2.7 \\
\hline Cap bank (S. No. 3) & 10.7 & 3.7 & 0.6 & 11.4 \\
\hline
\end{tabular}

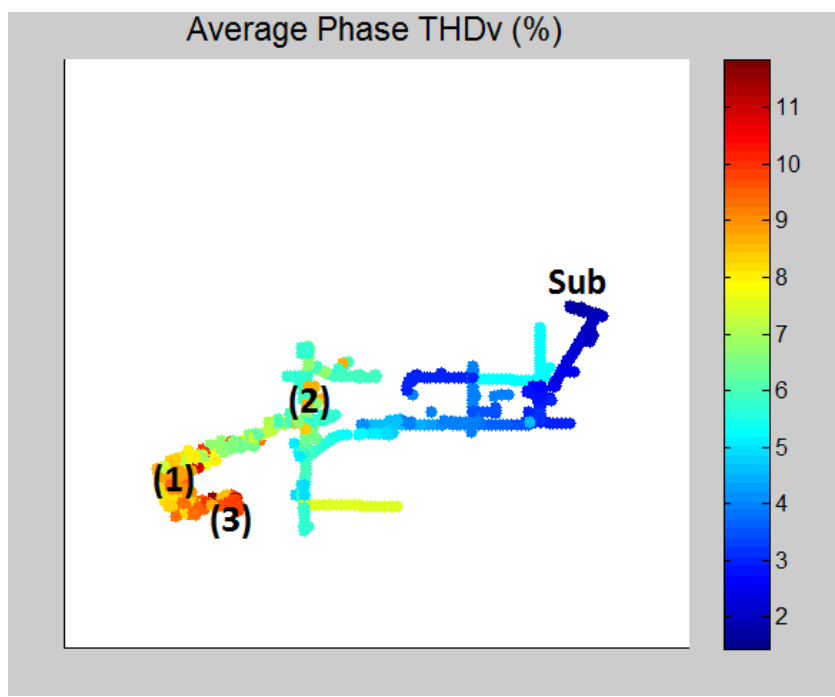

Fig. 4. Base Case Voltage THD Distribution Over Circuit C

The harmonic distortion analysis of the three selected circuits tells us that each circuit has a unique voltage distortion response to the distributed current harmonic sources. The response is not uniform over the length of the entire circuit so the response at circuit end may be quite different from what is found at circuit head. The response is primarily influenced by the strength of the upstream system and the sizes and locations of capacitor banks. Also, the status of the individual capacitor banks will determine the level of magnification of individual harmonic voltages.

\section{Developing a Repeatable Harmonics Estimation Framework}

This section presents EPRI's on-going work to create a framework for estimation of future harmonics levels on modern distribution systems. The analysis environment, called the Grid-IQ Harmonic Evaluation Module (HEM), provides a standardized interface to OpenDSS and provides a user-friendly tool for performing basic harmonic analyses including conducting frequency scans and solving for harmonic distortion in order to evaluate the system impacts of conventional and newer harmonic rich loads. In order to achieve these objectives, the software interface will allow the user to select the desired circuit and load models including harmonic spectra from an extensive library that has been built under the Grid-IQ platform and is provided along with the application.

Value and benefits that are pursued by the Grid-IQ HEM software include:

- The ability to perform detailed harmonic analyses including the ability to evaluate system (both location specific and feeder-wide) impacts of newer distributed harmonic sources

- The user does not need to install any licensed software platform to be able to use this tool 
- The user does not need the working knowledge of OpenDSS software in order to use the tool

And illustration of the basic user interface for the HEM is shown in Figure 5.

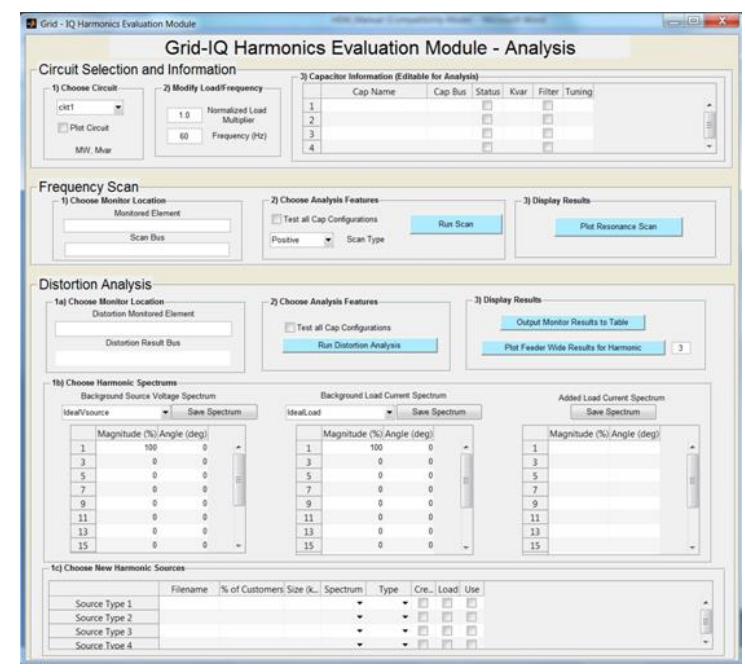

Fig. 5. Harmonics Evaluation Module - User Entry Screen

Through this input screen, the user can load any desired circuit model from the Grid-IQ OpenDSS library by making a selection from the drop-down list in "Choose Circuit" window in the analysis interface. Doing so will populate the fields for active and reactive power in the window itself. It will also populate the information about all the capacitor banks on the selected circuit in the form of a list in "Capacitor Information" window with the following attributes:

- Capacitor Name : Name of capacitor in OpenDSS model

- Capacitor Bus: Connecting bus in OpenDSS model

- Status : Connected, if checked (default option)

- Kvar : Capacitor bank size

- Filter: Filter configuration if checked, pure cap otherwise (default option).

- Tuning: Tuning harmonic frequency in pu, applicable if filter configuration is chosen.

In addition, a text box will display the system frequency in $\mathrm{Hz}$. Also, a text box titled "Normalized load multiplier" can be used to specify the global load multiplier that can be used to adjust the overall loading of the circuit. Default value for this multiplier is 1.0 signifying the peak loading conditions.

Checking the "Plot Circuit" option creates a plot representing the physical layout of the circuit primary conductors. It will also identify the location of the feeding substation and the individual capacitor banks. The row number in the capacitor table correlates to the location of the bank in the plot by the number of yellow dots. The plots shown in Figures 1-3 above were creating using the HEM tool. The thickness of individual line sections in the plot represents the magnitude of power flow through them. Dashed lines represent single- and two-phase line sections.

A number of practical elements have been incorporated into this analysis module in an attempt to create a flexible analysis environment that can be practically applied by electric utilities:

- Background harmonics levels: The tool incorporates the ability to add a "background" level of voltage harmonics. This enables the analysis to reflect "initial conditions" as well as allow for sensitivity analysis based on different starting points.

- Dynamic load mixes: The tool incorporates EPRIdeveloped harmonic load profiles based on laboratory testing. This allows the user to configure custom mixes of different types of CFLs, Rooftop PV, HEV chargers, and other harmonics-contributing loads, and to do multiple analyses for Low/Mid/High sensitivity analyses.

- OpenDSS models: The tool incorporates several dozen "standard" grid models to allow back-of-the-envelope analyses without having to incorporate custom grid models. However, the availability of OpenDSS converters for many proprietary grid modeling platforms offers the prospect of the user importing their own existing grid models for detailed custom analysis.

- Custom capacitor and filter bank profiles: The HEM allows the user to not only switch individual capacitor banks in and out of service, it also provides for testing the impact of converting individual capacitor banks to filter banks and the impact of that change on harmonic performance.

\section{Conclusions and Recommendations}

There is a growing need in the electric power industry for the ability to not only measure harmonics levels, but to be able to estimate future levels based on changing circumstances.

Increasingly, analysis tools for managing harmonics and other PQ phenomena will have to contend not only with static grid models, but with circuits and grids that are changing dynamically and, perhaps, rapidly based on changing market and operational circumstances.

\section{Acknowledgement}

The authors gratefully acknowledge the guidance of the members of EPRI Power Quality program for defining the scope of this work. 


\section{References}

[1] William Howe. Program Manager, Electric Power Research Institute (EPRI), 1919 8th Street, STE 202, Boulder CO USA 80302

[2] Matthew Rylander, Technical Leader, Electric Power Research Institute (EPRI), 3420 Hillview Avenue, Palo Alto, CA USA, 94304

[3] OpenDSS Program, Available on SOURCEFORGE.NET,

URL:http://sourceforge.net/projects/electricdss

[4] H. Sharma, W.G. Sunderman, and A. Gaikwad, "Harmonic Impacts of Widespread Use of CFL Lamps on Distribution Systems," in Proc. IEEE Power and Energy Society General meeting, San Diego, CA, 2011

[5] Grid IQ Harmonic Evaluation Module: EPRI, Palo Alto, CA: 2012. 1025485.

[6] IEEE Draft Guide for Applying Harmonic Limits on Power Systems, IEEE Standard p519.1/D12, July 2012.

[7] U.S. Energy Information Administration (2011, May), "Annual energy Outlook 2011 with projections to 2035," Available :www.eia.gov/forecasts/aeo/ 